\title{
Creating the Structure and Properties of 7075 Alloy Casts by Thermal and Forming Processes
}

\author{
Krzysztof Majerski ${ }^{1}$, Anna Dziubińska ${ }^{1 *}$, Grzegorz Winiarski ${ }^{1}$, Michał Szucki ${ }^{2}$ \\ Krzysztof Drozdowski
}

1 Lublin University of Technology, Faculty of Mechanical Engineering, ul. Nadbystrzycka 36, 20-618 Lublin, Poland

2 AGH University of Science and Technology in Cracow, Faculty of Foundry Engineering, ul. Reymonta 23, Building \# D8, 30-059 Cracow, Poland

3 ZOP Co. Ltd Forging Plant, ul. Kuźnicza 13, 21-045 Świdnik, Poland

* Corresponding author's e-mail: a.dziubinska@pollub.pl

\begin{abstract}
In this paper, the hot formability of 7075 aluminum alloy sand and permanent casting ingots were verified. The experiment was carried out by using casting, heat treatment (homogenization) of ingots and conducting isothermal compression tests at temperatures of $420-500^{\circ} \mathrm{C}$. The effect of the forming temperature on the microstructure, the tendency for crack formation and hardness were determined. The results show that ingots in the as-cast state have a dendritic network structure rich in the second phase precipitation on the grain boundaries. After the homogenization process, the microstructure is significantly more balanced. The forming process at $420-480^{\circ} \mathrm{C}$ of sand casts leads to significant grain elongation and crack formation, mainly at the grain boundaries. Raising the forming temperature to $480-500^{\circ} \mathrm{C}$ leads to a reduction in the occurrence of cracks. On the other hand, permanent mold castings do not reveal cracks during deformation in the temperature range $420-480^{\circ} \mathrm{C}$.
\end{abstract}

Keywords: Aluminum alloys, Heat treatment, Metal Forming, Microstructure

\section{INTRODUCTION}

Nowadays, aluminum alloys are widely used in the industry owing to their properties and the availability of many forming techniques, including casting, metal forming and machining $[1,16$, 18]. Aluminum alloys have low density and high corrosion resistance. In addition, their mechanical properties can be shaped to a great extent due to the possibility of using a numerous group of alloying elements and the thermal workability of many of these alloys [8].

The 7075 is an $\mathrm{Al}-\mathrm{Zn}-\mathrm{Mg}-\mathrm{Cu}$ aluminum alloy characterized by excellent mechanical properties such as high strength, and stress corrosion cracking resistance. The aforementioned alloy is used for manufacturing the parts used in the aviation and automotive industry $[7,15]$.
However, the high strength properties go hand in hand with limited formability, which is significantly lower than in the 5xxx and 6xxx alloys [3]. The limited cold-forming options [11], temperature sensitivity during hardening [13] as well as susceptibility to cracking at high strain rate [2] are the main obstacles in using the 7075 alloy more widely in the automotive industry.

As far as the 7075 alloy is concerned, the major hardening operation is solution heat treatment and ageing, which leads to the creation of fine precipitates [12], whereas the strain-caused fragmentation of grain and hardening work are of lesser significance, since dislocations are the preferred areas of distribution of supersaturated solutions [14].

Traditionally, extruded rods, sheets and plates [1] are subjected to plastic forming. Typical technological process for the 7075 alloy consists of: 
ingot homogenization and extruding of the semifinished product, annealing, forming and, later on, heat treatment, which causes the process to be complicated and expensive [11].

Therefore, numerous studies are conducted to increase the technological effectiveness of the 7075 alloy forming. Paper [12] presents the results of the research on lowering the forming temperature of deep-drawn sheets. It was stated that using thin sheets and limiting the temperature to $220^{\circ} \mathrm{C}$ causes no significant decrease in the mechanical parameters. As a result, additional heat treatment can be omitted. The authors of the article [11] present the results of the process of forming car brackets, made of T6 state 7075 alloy. It was stated that blank and tool temperature is equal to $240^{\circ} \mathrm{C}$ and enough to obtain the proper geometry of the end product. Due to the insignificant decrease of the mechanical properties caused by temperature growth conducting other heat treatment processes is economically unjustifiable.

The article [20] presents the results of the research on formability and mechanical properties of aluminium alloy 7075 sheets in the hot stamping process. The best results were observed for $400^{\circ} \mathrm{C}$ and forming velocity equal to $50 \mathrm{~mm} / \mathrm{s}$.

Forming of thin, heat treated aluminium sheets is a well-known process for the discussed alloy. The majority of the occurring problems are connected to volume forming.

The article [14] presents the possibility of applying hot thermo-mechanical processing HMTP, which allows for achieving a synergistic effect of precipitate hardening and grain refinement, which leads to obtaining better combinations of ductility and strength in comparison to the T6 treatment.

Furthermore, the methods for improving the properties of the product are introduced, e.g. by decreasing the grain volume as a result of multiple deformations. However, they are, dedicated mostly to the processes in which the billet is in the form of extruded semi-finished product [9] and are not focused on increasing the technological effectiveness of the process, but on obtaining the best possible properties.

Currently, an increased interest in the methods incorporating the casting and plastic treatment processes can be observed [10]. It is possible to manufacture ingots close in shape to the final product, the shape and dimensions of which are defined in forging. The plastic treatment of the ingot results in better mechanical properties as well as structure. Moreover, the research on in- tegrated casting-forming processes is conducted for the use of automotive industry [21].

The authors of the work [6] suggest applying semi-continuous casting in order to obtain semifinished products for plastic working.

In the article [17] a comparison of the forming possibilities of the 7075 aluminium alloy, attained using the direct chill casting method with and without homogenization, is presented. It was observed that despite the occurrence of secondary phases $(\mathrm{MgZn} 2)$, the non-homogenized ingots had smaller areas of unsteady flow on process maps, whereas in the case of temperatures above $300^{\circ} \mathrm{C}$ even applying the strain rate equal to $10 \mathrm{l} / \mathrm{s}$ did not cause the material to crack during compression.

According to the authors of the article [4], using the cast billets made of the 7075 aluminum alloy in the forging process allows for reducing the time of the technological process. The dendritic structure significantly decreases the ideality factor, mostly due to temperature sensitivity and susceptibility to cracking. It was suggested that the temperature within the range $425-465^{\circ} \mathrm{C}$ and strain between $0.01-11 / \mathrm{s}$ is suitable. Moreover, the possibility of applying different criteria for anticipating cracking was verified.

According to the authors of the article [4] the possibility of using the batch in the form of castings for the metal and sand molds would allow for a significant reduction in the technological costs in the case of the 7075 aluminum alloy. The possibility of applying the aforementioned technology to other alloys is currently researched $[5,20]$. Sand moulds are more suitable for small lot production, whereas the ingots for metal moulds can be used in manufacturing more products.

The objective of this study is to investigate the hot workability of the EN AW7075 alloy in the form of the sand mould and metal mould casts in terms of obtaining an advantageous microstructure.

\section{MATERIALS AND METHODS}

In the research, the 7075 aluminum alloy, obtained from an extruded rod was used. It was melted in a resistance furnace and, later on, poured into sand and metal moulds. The chemical composition of the alloy was presented in Table 1.

Each time, the metal was melted in a corundum crucible using a resistance furnace and heated to $750^{\circ} \mathrm{C}$. 
Table 1. The 7075 alloy - chemical composition according to [EN 1706:2010 (E)]

\begin{tabular}{|c|c|c|c|c|c|c|c|c|c|c|}
\hline Symbol & $\mathbf{C u}$ & $\mathbf{C r}$ & $\mathbf{F e}$ & $\mathbf{M g}$ & $\mathbf{M n}$ & $\mathbf{S i}$ & $\mathrm{Ti}$ & $\mathbf{Z n}$ & Al & Other \\
\hline 7075 & $1.2-2$ & $0.18-0.28$ & Max 0.5 & $2.1-2.9$ & Max 0.3 & Max 0.4 & Max 0.2 & $5.1-6.1$ & Rest & 0.15 \\
\hline
\end{tabular}

The aluminum alloys were cast into metal and sand mould (Fig 1a-b). The sand molds made of green sand with about $5 \%$ of water content (Fig. 1a) as well as steel permanent mold heated up to $300^{\circ} \mathrm{C}$.

The castings had the shape of a cylinder with the dimensions of $\phi 32 \times 80 \mathrm{~mm}$. A K-type thermocouple was placed in the geometric center of the casting (Fig 1b), which enabled the temperature measurement during solidification and cooling process.

After pouring the metal into moulds, it was left there for ca. 30-45 min and then extracted. The casting was then subjected to machining in order to obtain the samples for the hot compression test, whereas from the central parts of the rolls, the samples for microstructural testing were attained. The samples for hot compression were subjected to homogenization at $475^{\circ} \mathrm{C}$ for $24 \mathrm{~h}$ in order to obtain a homogenous chemical composition. The temperature of billet was set to 420, 440, 460, 480 and $500^{\circ} \mathrm{C}$ in order to determine the range of workability of the 7075 alloy. The forging tests were performed in accordance with the PN-H-04411:1983 standard by means of an open-die hot forging on a hydraulic press, Nargesa MX-700 (Fig 2a).

The roll samples with the dimensions $d_{0} \times h_{O}$ (20x30 mm) in accordance with the dependency (2.1) were deformed in line with the scheme in Fig.

a)

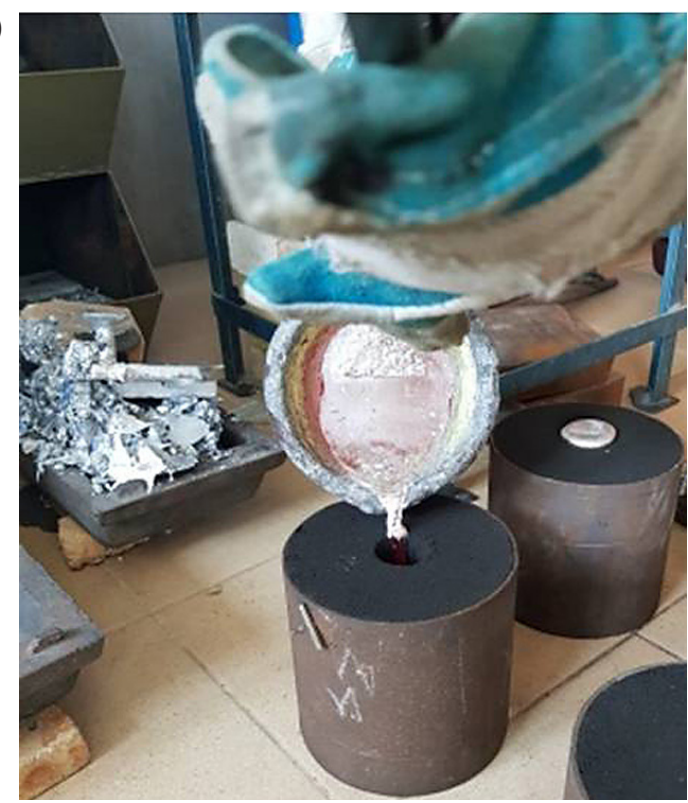

$2 \mathrm{~b}$ to the final height $h_{1}$ described by the dependency (2.2). The tools remaining in the direct contact with the material were heated to $250^{\circ} \mathrm{C}$, strain rate was equal $8 \mathrm{~mm} / \mathrm{s}$. The analysis involved investigation of alloy workability, its susceptibility to crack occurrence, the hardness and changes of alloy microstructure during the forming process.

In order to create the metallographic samples, the material fragments were cut using a cutter with water cooling system and abrasive blades for cutting non-ferrous metals. The obtained fragments were mounted in resin and subjected to grinding and polishing processes.

The initial grinding was conducted on grinding discs with granularity 220, 500 and 1200 . Further on the samples were polished using diamond slurry with granularity equal to $3 \mu \mathrm{m}$ and alumina powder in colloidal silica suspension with granularity $0.05 \mu \mathrm{m}$. After such treatment, the sections were etched by Keller's reagent: $95 \mathrm{ml}$ distilled water, $2.5 \mathrm{ml} \mathrm{HNO3,} 1.5 \mathrm{ml} \mathrm{HCl}, 1.0 \mathrm{ml} \mathrm{HF}$.

The tests were conducted using the cross-sections of the roll samples as well as the cross-sections of the forgings. The observations were carried out in central and surface parts of the roll samples, whereas in the case of the forgings the central, the surface and side parts of the samples were observed.

b)

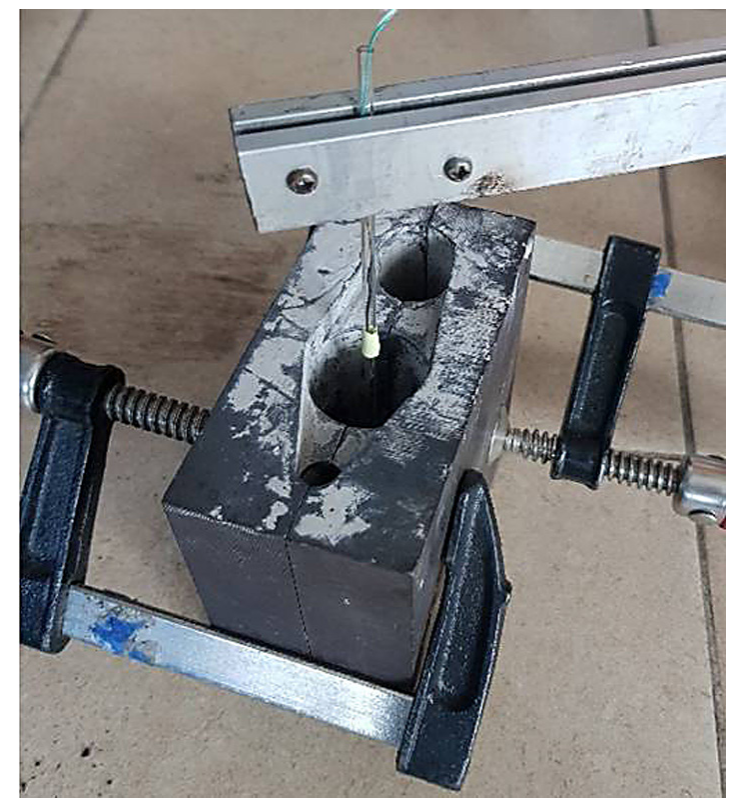

Fig. 1. Process of casting a) in a sand mould b) in a permanent mould 


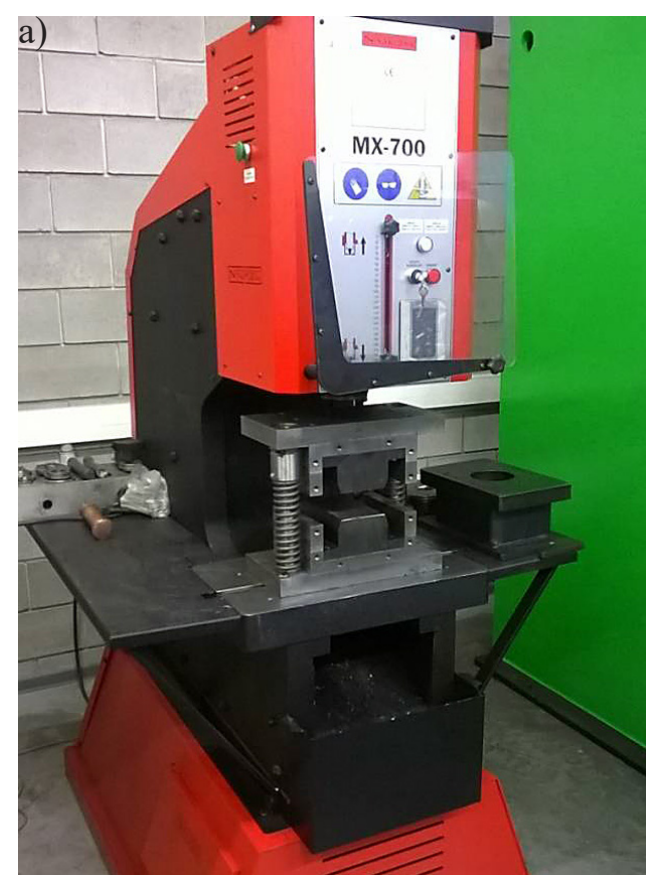

b)

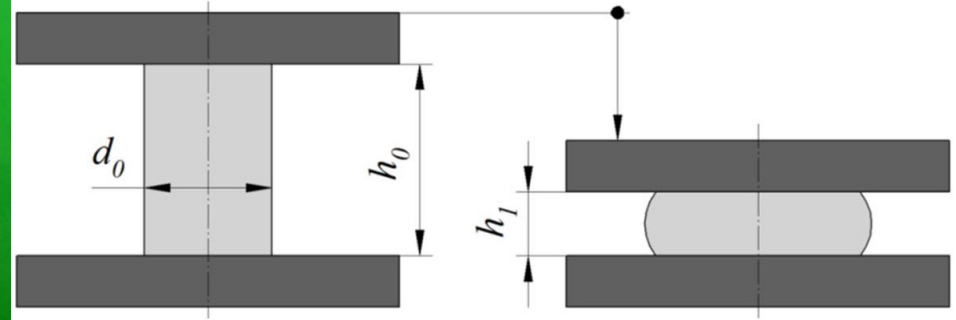

$$
\frac{h_{0}}{d_{0}}=1,5 \quad(2.1), \quad h_{1}=\frac{1}{3} \cdot h_{0}
$$

Fig. 2. a) Hot compression stand, b) Hot compression sample scheme

The Nikon MA200 optical microscope and Phenom proX scanning electron microscope were used in the microstructure analysis. The hardness tests were conducted using the Vickers method. The measurements were taken using the FM800 Future-tech hardness tester. The measurements were taken in HV1 scale, in compliance with PNEN ISO 6507-1:2006.

\section{RESULTS}

Figure 3 presents the castings as well as the cooling curves obtained for the sand and metal mould. Upon analysing the cooling curves, a significant difference between the cooling rate of the alloy in sand and metal moulds was observed. Cooling in a metal mould is much faster. On the basis of the obtained cooling curves, the approximate setting times in sand moulds and dies (Table 2) were established (based on DTA analysis).

Table 2. Estimated setting time in sand moulds and dies

\begin{tabular}{|c|c|}
\hline Mold type & Time [s] \\
\hline Sand & 437 \\
\hline Permament & 29 \\
\hline
\end{tabular}

a)

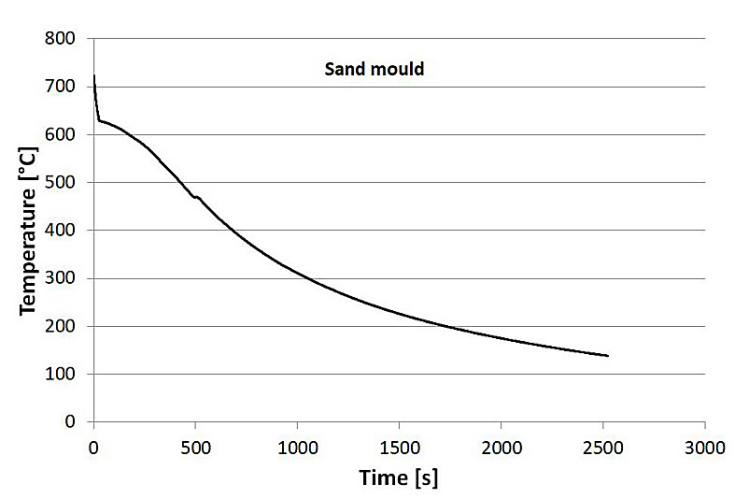

b)

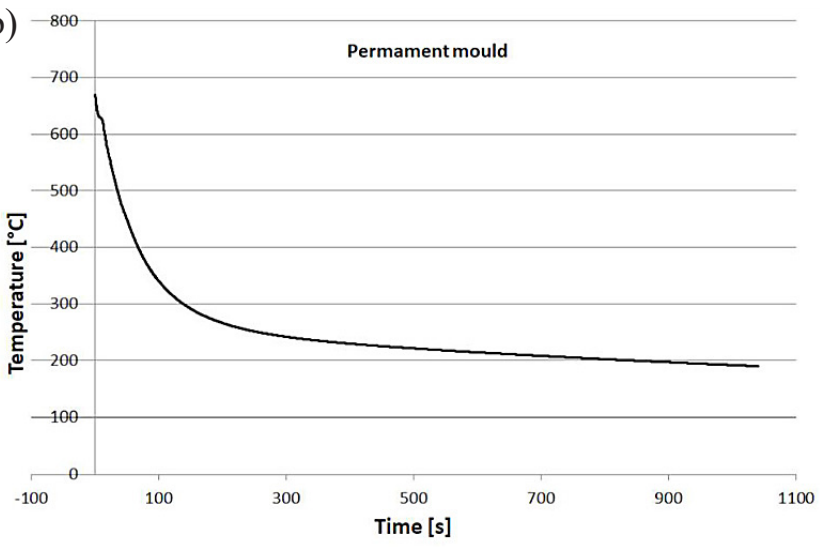

Fig. 3. Cooling curves for the 7075 alloy: a) sand mould, b) metal mould 
Table 3. Microstructures of the material after casting and homogenization (SEM)

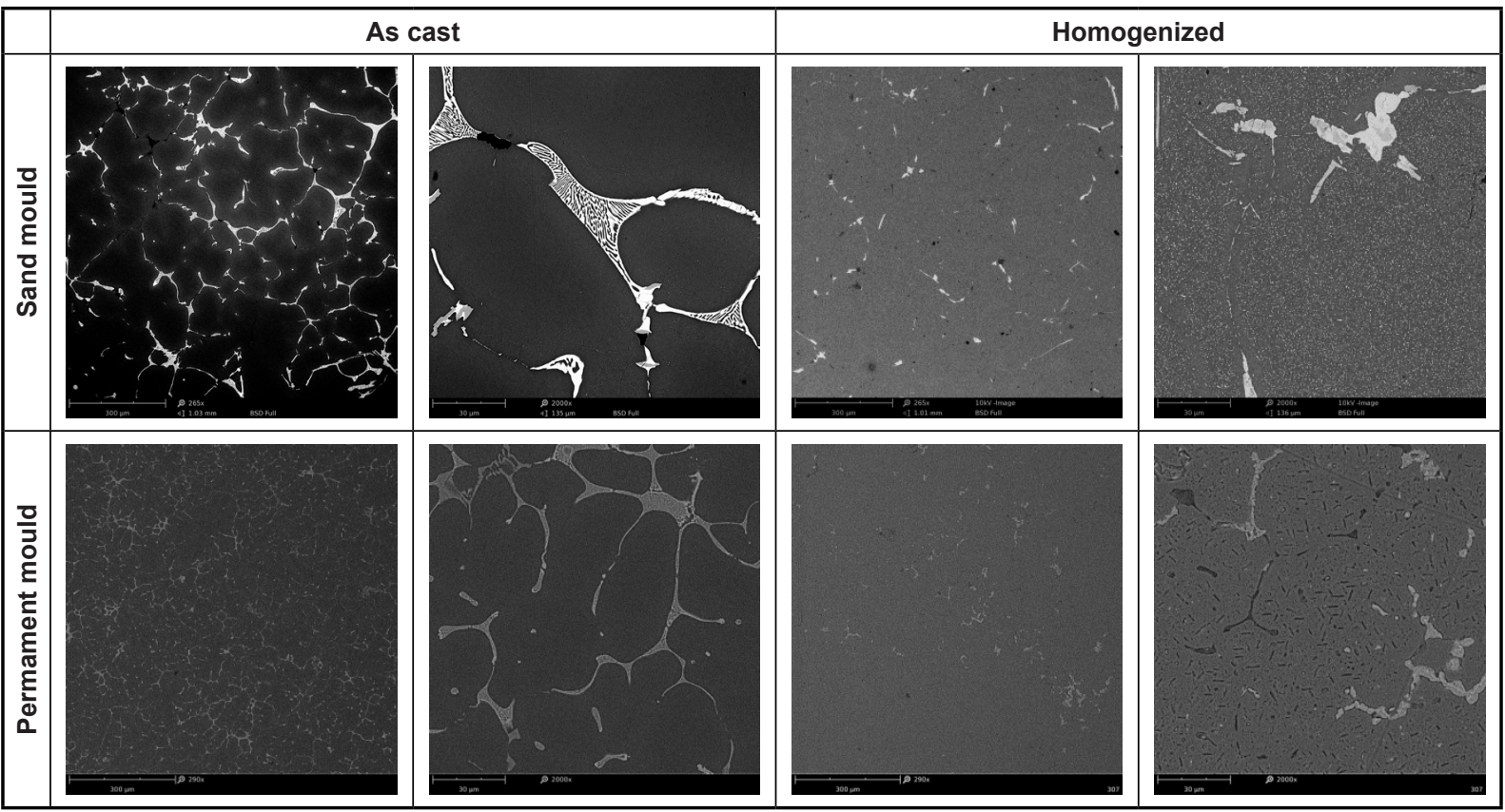

The setting time of the casting in a sand mould is significantly longer than for the metal mould. This phenomenon is caused by a significant difference in thermal conductivity of the material of the mould and can influence the structure of the casting. A microstructural analysis of the materials after casting and homogenization was conducted on non-etched sections, using a scanning microscope. Table 3 presents a comparison of the microstructure obtained using SEM during the observation of the non-etched sections.

After casting, the microstructures are dendritic. Along the boundaries of grains, numerous eutectic precipitations, consisting of intermetallic phases are to be observed. As far as a casting from a sand mould is concerned, both grains and precipitations are larger. As a result of the homog- enization process, dissolution of eutectics and a significant number of intermetallic precipitations can be observed. The homogeneity of alloys was considerably increased, which indicates that the strain possibility is higher. The remainders of the undissolved precipitations are more significant in the case of the sand mould.

An assessment aluminum alloy susceptibility to plastic deformation was conducted by the means of visual evaluation of castings, carried out with the unaided eye after upsetting and a microstructural analysis.

Table 4 presents the photographs of the samples after hot compression tests. An analysis of the side surface of the samples showed that for each upsetting temperature the samples from the sand moulds show cracks or crack centres. How-

Table 4. Test surface of the samples after hot compression test

\begin{tabular}{|c|c|c|c|c|c|}
\hline & $420^{\circ} \mathrm{C}$ & $440^{\circ} \mathrm{C}$ & $460^{\circ} \mathrm{C}$ & $480^{\circ} \mathrm{C}$ & $500^{\circ} \mathrm{C}$ \\
\hline 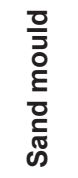 & & & & & \\
\hline 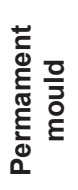 & r & & & & \\
\hline
\end{tabular}


Table 5. Microstructures of the cross-sections after upsetting

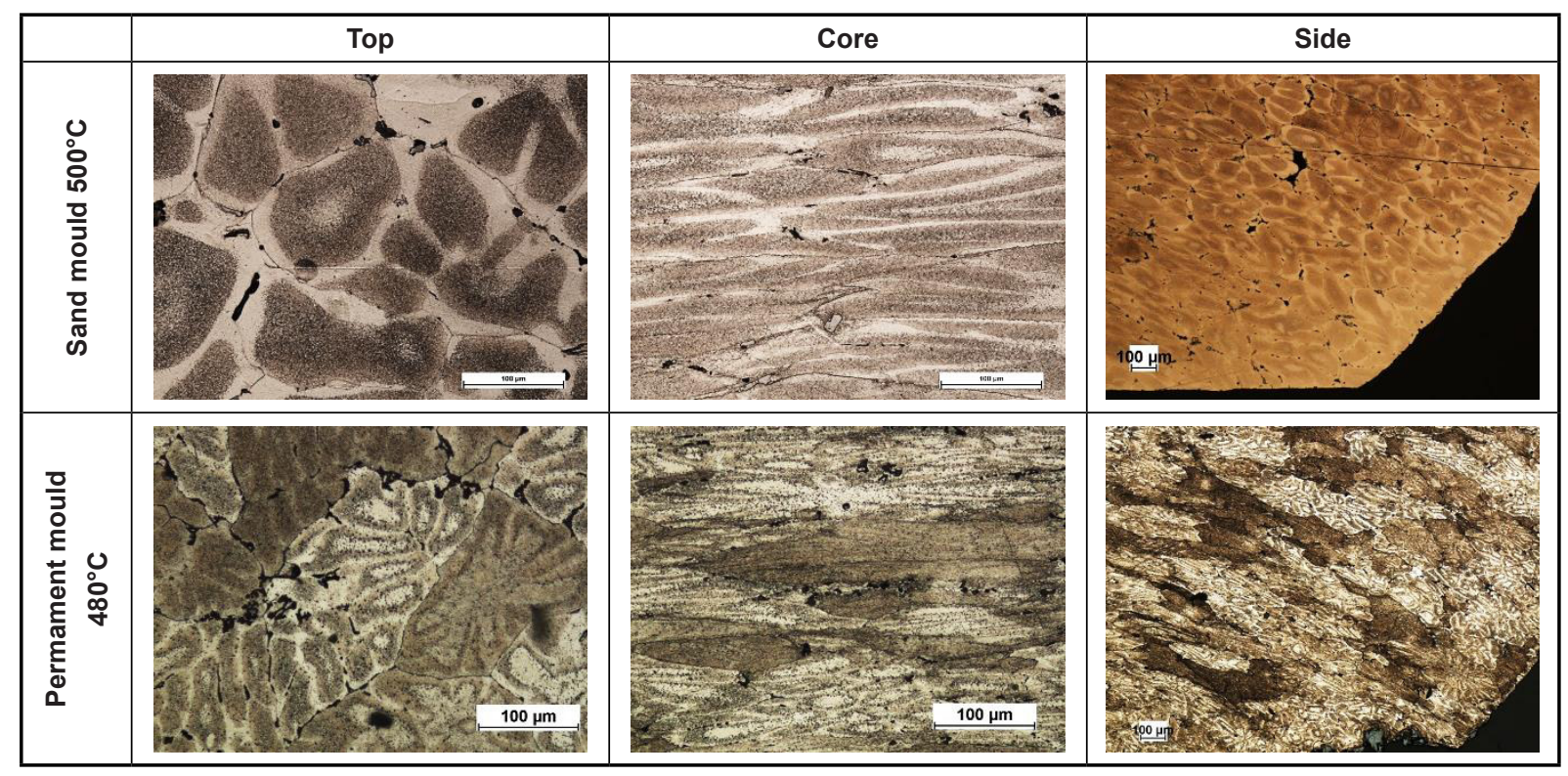

ever, in the case of the samples upset at $500^{\circ} \mathrm{C}$, the loss of structural integrity is the least significant. Therefore, it can be assumed that this temperature is the most suitable for deforming the 7075 aluminium alloy in a sand mould. The evaluation of the side surface of the samples from metal moulds, acquired in the temperature range between $420-480^{\circ} \mathrm{C}$ showed no signs of cracking. The only cracks detected occurred on the side surface of the sample deformed at $500^{\circ} \mathrm{C}$.

Table 5 shows the microstructures of selected areas of the upset forging's the cross sections.

In the top of the upset forgings, both from the sand and metal moulds, a majority of original equiaxed grains of a varied size can be noticed. In the boundaries of the grains one can observe undissolved intermetallic phases. In the case of the sand mould castings, those phases are significantly larger. The range of strain and deformation of grains is insignificant in this area. The size of grains did not change after the homogenization process.

In the central area of the upset forging, a significant deformation of the grains occurs. However, the grains show signs of dynamic recovery. As far as a casting from a sand mould is concerned, a significant number of precipitations from intermetallic phases can be observed in the boundaries of grains, which show no signs of deformation.

The side areas of the upset forgings show an average deformation ratio as far as the castings from sand mould are concerned. In this type of casting, one can notice that the areas of inconsistency are located in the boundaries of grains, showing the characteristics of the cracks, occurring inside and advancing towards the surface.

In the central areas of the samples, the hardness tests were conducted. Table 6 presents the results of the measurements. Upon analysis of the results of the hardness test it was stated that the castings from sand moulds are harder than the ones obtained from permanent moulds. Moreover, immediately after casting, the samples showed the highest values of standard deviation, which indicates its inconsistent structure. After the homogenization process, the hardness of the product decreased significantly, for the sand and permanent moulds by $38 \%$ and $22 \%$, respectively. As a result of hot deformation and rapid cooling, the hardness of the products increases again, reaching the values of $132.8 \mathrm{HV}$ for the sand form and $135.7 \mathrm{HV}$ for metal form.

Table 6. Results of the hardness tests

\begin{tabular}{|c|c|c|c|c|c|c|}
\hline \multirow{2}{*}{ Description } & \multicolumn{2}{|c|}{ As cast } & \multicolumn{2}{c|}{ Homogenized } & \multicolumn{2}{c|}{ Hot compressed } \\
\cline { 2 - 7 } & Sand mould & Permament mould & Sand mould & Permament mould & Sand mould & Permament mould \\
\hline $\begin{array}{c}\text { Average Hardness } \\
\text { HV1 }\end{array}$ & 138 & 111.1 & 94,1 & 86.6 & 132.8 & 135.7 \\
\hline Std. Deviation & 3.5 & 7.9 & 2.8 & 1.7 & 2.7 & 2.6 \\
\hline
\end{tabular}




\section{CONCLUSIONS}

The article presents the results of research on using the castings from sand and metal moulds with the 7075 aluminium alloy as charge material for forging in the temperature ranging from $420-500^{\circ} \mathrm{C}$.

On the basis of the research it was stated that:

- The differences in microstructure of the castings from different moulds occur, mainly a larger size of grains as well as precipitations of the intermetallic phases in sand moulds that do not dissolve entirely in the homogenization process.

- The results of hot compression test indicate that the castings from sand moulds are more prone to cracking in of the side surface of upset forgings in the researched range of temperature.

- In the case of upset forgings from sand moulds, the cracks occur in the boundaries of grains, in the areas of significant precipitation of the intermetallic phases.

- The castings from sand moulds ought to be subjected to a longer homogenization process or the deformation reduced.

- The non-homogeneous microstructure between the different areas of upset forgings indicates that it is necessary to form the casting in such a way that allows for obtaining the possibly most similar level of deformation in the entire billet.

\section{ACKNOWLEDGMENTS}

Project "The Design and Implementation of an Innovative Low-Waste Metal Forming Technology for High-Strength Light Metal Alloys Used in the Aircraft and Automotive Industry"; No. LIDER/10/0058/L-8/16/NCBR/2017. Total cost of the Project: 1,200,000 PLN. The project is financed by the National Centre for Research and Development under the 8th edition of the LIDER Programme.

\section{REFERENCES}

1. Davis, J.R.: ASM Specialty Handbook: Aluminum and Aluminum Alloys. (1993).

2. G.W. Kuhlman: Forging of aluminum alloys. ASM Handbook, Vol. 14A Metalwork. Bulk Form. (2005). https://doi.org/10.1361/asmhba0003996.

3. George, E.T., MacKenzie, D.S.: Handbook of Aluminum: Volume 2: Alloy Production and Materials Manufacturing, (2003).

4. Guo, L. et al.: Processing map of as-cast 7075 aluminum alloy for hot working. Chinese J. Aeronaut. (2015). https://doi.org/10.1016/j.cja.2015.08.002.
5. Kim, H.. et al.: A study of the manufacturing of tie-rod ends with casting/forging process. J. Mater. Process. Technol. 125-126, 471-476 (2002). https://doi.org/10.1016/S0924-0136(02)00323-0.

6. Kwak, Z. et al.: Microstructure of selected 7xxx series aluminum alloys obtained by semi-continuous casting. Pr. Inst. Odlew. 56, (2016).

7. Moćko, W., Kowalewski, Z.L.: Dynamic properties of aluminium alloys used in automotive industry. J. KONES. 19, 345-351 (2012).

8. Mondolfo, L.F.: Aluminum alloys: structure and properties. Elsevier (2013).

9. Naser, T.S. Ben, Krallics, G.: Mechanical behavior of multiple-forged Al 7075 aluminum alloy. Acta Polytech. Hungarica. 11, 7, 103-117 (2014).

10. Płonka, B. et al.: Application of Al alloys, in the form of cast billet, as stock material for the die forging in automotive industry. Arch. Civ. Mech. Eng. (2008). https://doi.org/10.1016/S1644-9665(12)60201-5.

11. Polak, S. et al.: Warm forming of 7075 aluminum alloys. Procedia Eng. 207, 2399-2404 (2017).

12. Porter, D.A. et al.: Phase Transformations in Metals and Alloys, (Revised Reprint). CRC press (2009).

13. Robinson, J.S. et al.: The influence of quench sensitivity on residual stresses in the aluminium alloys 7010 and 7075. Mater. Charact. (2012). https://doi. org/10.1016/j.matchar.2012.01.005.

14. Segal, V.M.: New hot thermo-mechanical processing of heat treatable aluminum alloys. J. Mater. Process. Technol. 231, 50-57 (2016). https://doi. org/10.1016/J.JMATPROTEC.2015.12.009.

15. Starke, E.A., Staley, J.T.: Application of modern aluminum alloys to aircraft. Prog. Aerosp. Sci. 32, 2-3, 131-172 (1996). https://doi. org/10.1016/0376-0421(95)00004-6.

16. Totten, G.E., MacKenzie, D.S.: Handbook of Aluminum: Vol. 1: Physical Metallurgy and Processes. CRC press (2003).

17. Wang, H. et al.: Warm forming behavior of high strength aluminum alloy AA7075. Trans. Nonferrous Met. Soc. China (English Ed. (2012). https:// doi.org/10.1016/S1003-6326(11)61131-X.

18. Winiarski, G. et al.: The influence of tool geometry on the course of flanges radial extrusion in hollow parts. Arch. Civ. Mech. Eng.17, 4, 986-996 (2017). https://doi.org/10.1016/j.acme.2017.04.002.

19. Xiao, W.-C. et al.: Deep drawing of aluminum alloy 7075 using hot stamping. Rare Met. 36, 6, 485-493 (2017). https://doi.org/10.1007/s12598-017-0919-4.

20.Zhou, H.T. et al.: A study of automobile brake bracket formed by casting-forging integrated forming technology. Mater. Des. (2015). https://doi. org/10.1016/j.matdes.2014.11.046.

21. Zhou, H.T. et al.: A study of automobile brake bracket formed by casting-forging integrated forming technology. Mater. Des. 67, 285-292 (2015). https://doi.org/10.1016/J.MATDES.2014.11.046. 